\title{
Economic Dispatch Pada Pembangkit Listrik Tenaga Diesel Gas (PLTDG) Menggunakan Fuzzy Logic Controller (FLC)
}

\author{
I Made Teguh Winasatria ${ }^{1}$, I Made Mataram ${ }^{2}$, Ida Bagus Gede Manuaba ${ }^{3}$ \\ [Submission: 30-01-2019, Accepted: 12-04-2019]
}

\begin{abstract}
In every fulfillment of electricity needs, a power plant unit is operated using various fuels. But the biggest expenditure from the operation of the plant is on the cost of using the generator unit fuel which is around $60 \%$, so a solution is needed to minimize the cost of generating fuel in operating the generating unit. Economic Dispatch is a way to overcome the economic operating problem of a power plant by dividing the load on each operating unit in order to obtain minimum generation costs. The problem of Economic Dispatch can be done using the Fuzzy Logic Controller (FLC) method because the FLC method can make very complex decisions and in its application does not require mathematical models that are too difficult to solve, so that the FLC method is expected to minimize the cost of generating electricity. The results of calculating the Economic Dispatch using the FLC method result in a lower total production cost compared to the total total production cost of the System and the Lamda Iteration method for 24 hours on September 30, 2017.
\end{abstract}

Intisari-Dalam setiap pemenuhan kebutuhan energi listrik, dioperasikan unit pembangkit listrik menggunakan bahan bakar yang beragam. Pengeluaran biaya terbesar dari pengoperasian pembangkit ada pada biaya dari penggunaan bahan bakar unit pembangkit yakni sekitar 60\%, maka dari itu diperlukan solusi untuk dapat meminimalkan biaya penggunaan bahan bakar pembangkit dalam mengoperasikan unit pembangkit. Economic Dispatch merupakan suatu cara untuk mengatasi persoalan pengoperasian ekonomis pembangkit listrik dengan melakukan pembagian pembebanan pada tiap unit pembangkit yang beroperasi agar didapat biaya pembangkitan minimum. Pemecahan permasalahan Economic Dispatch dapat dilakukan dengan metode Fuzzy Logic Controller (FLC) karena metode FLC dapat membuat keputusan yang sangat kompleks dan pengaplikasiannya tidak membutuhkan model matematika yang sulit diselesaikan, sehingga dengan metode FLC ini diharapkan mampu meminimalkan biaya pembangkitan energi listrik. Hasil perhitungan Economic Dispatch dengan metode FLC menghasilkan total biaya produksi yang lebih murah dibanding dengan total biaya produksi Riil Sistem dan metode Iterasi Lamda selama 24 jam tanggal 30 September 2017.

Kata Kunci: Energi listrik, Economic Dispatch, Fuzzy Logic Controller

\section{PENDAHULUAN}

Dalam menjalankan pekerjaannya, manusia selalu membutuhkan energi misalnya energi listrik. Maka dari itu,

\footnotetext{
${ }^{1}$ Mahasiswa, Program Studi Teknik Elektro Fakultas Teknik Universitas Udayana, Jln. Anyelir Gg. Sita No. 8 Denpasar 80235. INDONESIA (telp: $\quad$ 082237288789; $\quad$ e-mail: winasatriateguh@gmail.com)

${ }^{2,3}$ Dosen, Program Studi Teknik Elektro Fakultas Teknik Universitas Udayana, Jalan Kampus Bukit Jimbaran 80361 INDONESIA telp: 0361-703315; fax: 0361-703315
}

permintaan terhadap energi listrik akan meningkat setiap tahun. Dalam pemenuhan kebutuhan energi listrik, dioperasikanlah unit pembangkit listrik dengan penggunaan bahan bakar yang beragam dan pengeluaran biaya terbesar dari total biaya pengoperasian pembangkit ada pada biaya penggunaan bahan bakar unit pembangkit yakni sekitar $60 \%$, maka dari itu diperlukan solusi untuk meminimalkan biaya penggunaan bahan bakar pembangkit dalam mengoperasikan unit pembangkit [1]. Sehingga dibutuhkan solusi dalam meminimalkan dan mengoptimalkan biaya penggunaan bahan bakar pembangkit listrik agar didapat nilai ekonomis pembangkitan energi listrik.

Economic Dispatch atau pengoperasian ekonomis adalah solusi untuk mengatasi permasalahan pengoperasian ekonomis pembangkit energi listrik dengan melakukan pembagian pembebanan pada unit-unit pembangkit yang beroperasi agar didapatkan biaya produksi energi listrik unit pembangkit yang minimum dan optimal dalam sistem kelistrikan [2]

Berbagai metode telah dikembangkan oleh para ahli bidang kelistrikan untuk memecahkan permasalahan pengoperasian ekonomis (Economic Dispatch) salah satunya adalah metode Fuzzy Logic Controller (FLC). FLC atau Logika Fuzzy merupakan suatu komponen pembentuk soft computing, dimana implementasi Fuzzy Logic terhadap penyelesaian persoalan pengoperasian ekonomis (Economic Dispatch) dan penjadwalan pembangkit telah banyak dilakukan penelitian. Hal ini karena metode FLC dapat membuat keputusan yang sangat kompleks serta pengaplikasiannya tidak membutuhkan model matematika yang sulit untuk diselesaikan, sehingga dengan metode FLC ini diharapkan mampu meminimalkan biaya pembangkitan energi listrik [3]. Maka dari itu dengan adanya penelitian Economic Dispatch menggunakan metode FLC pada unit PLTDG milik PT. Indonesia Power UPJP Bali, diharapkan mampu meminimalkan biaya penggunaan bahan bakar dalam proses pembangkitkan energi listrik.

Hasil biaya produksi perhitungan Economic Dispatch menggunakan metode FLC akan dibandingkan dengan data Real System dan metode Iterasi Lamda sehingga nantinya akan diketahui metode mana yang menghasilkan total biaya produksi yang lebih murah.

\section{A. Pembangkit Listrik Tenaga Diesel Gas (PLTDG)}

Pembangkit Listrik Tenaga Diesel Gas (PLTDG) adalah salah satu jenis pembangkit termal milik PT. Indonesia Power UPJP Bali Unit Pesanggaran. Unit PLTDG ini dapat beroperasi menggunakan salah satu dari tiga jenis bahan bakar yang berbeda yaitu HSD, MFO dan LNG. Saat ini unit yang 
tersedia adalah 12 unit PLTDG dengan total keseluruhan daya yang mampu dibangkitkan sebesar 200 MW. Jika dihitung lebih rinci setiap unit mampu membangkitkan daya rata-rata sebesar 16,67 MW. PLTDG merupakan jenis pembangkit yang cocok digunakan pada saat beban puncak karena mampu menghasilkan daya dalam waktu singkat yaitu sekitar 5 menit setelah mesin dihidupkan. Pengoperasian PLTDG saat melayani beban seluruhnya menggunakan bahan bakar gas dan dilakukan monitoring untuk mengetahui berapa total bahan bakar yang digunakan saat melayani beban dari awal mesin dioperasikan hingga mesin dimatikan.

\section{B. Karakteristrik Input-Output Pembangkit}

Setiap pembangkit memiliki karakteristik sendiri dalam pengoperasiannya. Dan diperlukan dasar mengenai karakteristik input-output unit pembangkit termal dalam menganalisis permasalahan operasi ekonomis. Karakteristik input-output pembangkit termal merupakan fungsi yang menunjukkan besarnya energi ( $\mathrm{H}$ : Heat rate characteristic) dalam satuan $\mathrm{Mbtu} / \mathrm{h}$ atau besarnya biaya bahan bakar (F: Production cost function) dalam satuan $\mathrm{Rp} / \mathrm{h}$ yang diperlukan untuk membangkitkan daya listrik (P: MW). Karakteristik input-output pembangkit termal dalam keadaan ideal dapat dilihat pada gambar 1 . Incremental heat rate characteristic of thermal unit merupakan fungsi yang menunjukkan peningkatan jumlah energi yang diperlukan untuk meningkatkan pembangkitan sebesar satu daya listrik. Turunan dari fungsi masukan energi terhadap daya listrik yang dibangkitkan adalah $\Delta \mathrm{H} / \Delta \mathrm{P}[4]$.

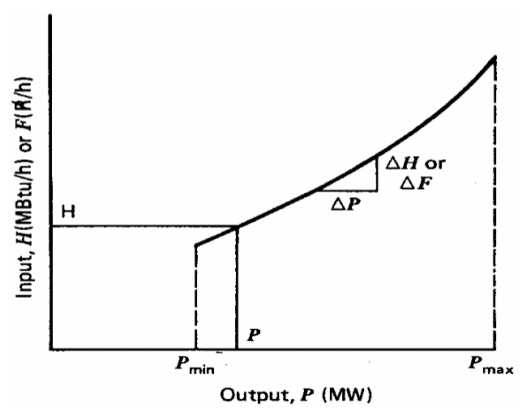

Gambar 1: Kurva input-output ideal suatu steam generator

Secara umum, karakteristik input-output pembangkit dapat diselesaikan dengan menggunakan fungsi polinomial orde dua:

$$
F_{i}\left(P_{i}\right)=a_{i}+b_{i} P_{i}+c_{i} P_{i}^{2}
$$

Dimana:

$\mathrm{Fi}(\mathrm{Pi})$ : biaya pemakaian bahan bakar unit pembangkit ke-i $(\mathrm{Rp} / \mathrm{h})$

Fi : Input bahan bakar pembangkit ke-i (Rp/jam)

Pi : Output pembangkit ke-i (MW)

ai, bi, ci : Konstanta input-output pembangkit ke-i

i : Indeks pembangkit ke-i $(\mathrm{i}=1,2,3, \ldots, \mathrm{n})$

\section{Economic Dispatch}

Pembangkit tenaga listrik memerlukan bahan bakar saat beroperasi beroperasi dalam memenuhi beban sistem. Agar didapat total biaya bahan bakar yang minimum maka biaya pembangkitan unit yang beroperasi juga harus diminimumkan
[5]. Economic Dispatch merupakan solusi untuk mengatasi permasalahan pengoperasian ekonomis pembangkit tenaga listrik dengan melakukan pembagian pembebanan pada tiap unit pembangkit yang beroperasi agar didapat biaya pembangkitan minimum terhadap produksi daya listrik dalam sistem kelistrikan.

Biaya dasar pembangkit (cost rate) merupakan input dari tiap unit pembangkit yang dinyatakan sebagai $F i(F 1, F 2, \ldots, n)$ seperti pada gambar 2. Daya listrik yang dibangkitkan merupakan output tiap unit pembangkit dinyatakan sebagai Pi $(\mathrm{P} 1, \mathrm{P} 2, \ldots, \mathrm{n})$.

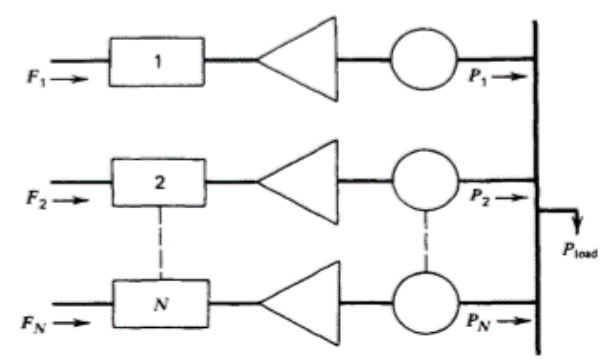

Gambar 2. Pembangkit termal $\mathrm{N}$ yang melayani beban $\mathrm{P}_{\text {load }}$

Secara matematis, FT merupakan total biaya pengoperasian unit pembangkit dalam memenuhi kebutuhan beban. Untuk meminimalkan biaya pembangkitan (FT) dengan catatan rugi transmisi diabaikan. Maka persamaannya adalah [6]:

$$
\begin{aligned}
& F_{T}=F_{1}+F_{2}+F_{\mathrm{a}}+\cdots+F_{N} \\
& F_{T}=\sum_{i=1}^{N} F_{i}\left(P_{1}\right)
\end{aligned}
$$

Dimana:

FT : total biaya pembangkit dalam sistem

$\mathrm{Fi}(\mathrm{Pi}) \quad$ : fungsi biaya unit pembangkit ke-i

$\mathrm{N} \quad$ : jumlah unit pembangkit

i : indeks pembangkit ke $\mathrm{i},(\mathrm{i}=1,2,3, \ldots . . \mathrm{N})$

\section{1) Economic Dispatch dengan Iterasi Lamda:}

Salah satu metode yang digunakan pada Economic Dispatch adalah Iterasi Lamda, dengan mengasumsikan nilai Lamda $(\lambda)$, kemudian dengan menggunakan syarat optimum, hitunglah nilai P1 (output tiap pembangkit). Kemudian lakukanlah penyamaan nilai output dari hasil perhitungan lamda dengan kebutuhan sistem. Apabila belum sama maka harga lamda harus ditentukan kembali [6].

\section{Fuzzy Logic Controller (FLC)}

Logika Fuzzy merupakan metode pemecahan masalah yang menggunakan operasi aturan dasar (rule base) dengan memproses beberapa variabel input dan output yang masuk akal pada sistem nonlinier dan sistem yang kompleks [7].

Logika Fuzzy diperkenalkan oleh Prof. Lotfi A. Zadef pada tahun 1965 sebagai suatu cara untuk memproses data yang menggunakan himpunan-himpunan keanggotaan, Lotfi A. Zadeh memodifikasi teori himpunan di mana setiap anggotanya memiliki derajat keanggotaan antara 0-1 yang disebut dengan himpunan Fuzzy [8]. Pada teori himpunan Fuzzy inilah yang menjadi ciri utama dalam penalaran logika fuzzy karena memiliki membership function [9]. 
Beberapa alasan mengapa Logika Fuzzy sering digunakan dalam beberapa penelitian, diantaranya adalah [10]:

1. Logika Fuzzy menggunakan konsep matematis sebagai dasar penalaran Fuzzy sehingga mudah dimengerti.

2. Logika Fuzzy sangat fleksibel.

3. Logika Fuzzy memiliki toleransi terhadap data-data yang tidak tepat.

4. Logika Fuzzy mampu memodelkan fungsi-fungsi non linear yang sangat kompleks.

5. Dengan Logika Fuzzy para pakar dapat mengaplikasikan pengalamannya tanpa melalui proses pelatihan.

6. Teknik kendali secara konvensional dapat dilakukan dengan Logika Fuzzy.

7. Bahasa alami menjadi dasar dalam Logika Fuzzy.

Logika Fuzzy dapat menjadi solusi dalam penyelesaian segala permasalahan yang banyak diaplikasikan dalam bidang kendali dan pemrosesan informasi. Logika Fuzzy memberikan cara sederhana dalam menentukan kesimpulan dari berbagai informasi yang tidak jelas dan tidak tepat. Kinerja Fuzzy dapat membuat keputusan melalui pendekatan data yang diketahui sebelumnya dan kemudian menentukan solusinya. Software pendukung untuk merancang program Logika Fuzzy adalah pada Matlab versi R2016a.

\section{1) Konsep Fuzzy Logic Fungsi Keanggotaan :}

Nilai keanggotaan (derajat keanggotaan) antara interval 0 - 1 diperlihatkan dalam suatu kurva dengan pemetaan titiktitik input. Dalam menentukan nilai keanggotaan dilakukan melalui pendekatan fungsi [9]. Penelitian ini menggunakan membership function dengan 2 tipe yaitu kurva segitiga (trimf) dan trapesium (trapmf). Kurva segitiga merupakan gabungan antara 2 garis (linear), seperti terlihat pada gambar 3 . Sedangkan Kurva trapesium seperti bentuk segitiga, hanya saja ada titik yang memiliki nilai keanggotaan 1, Seperti terlihat pada gambar 4 .
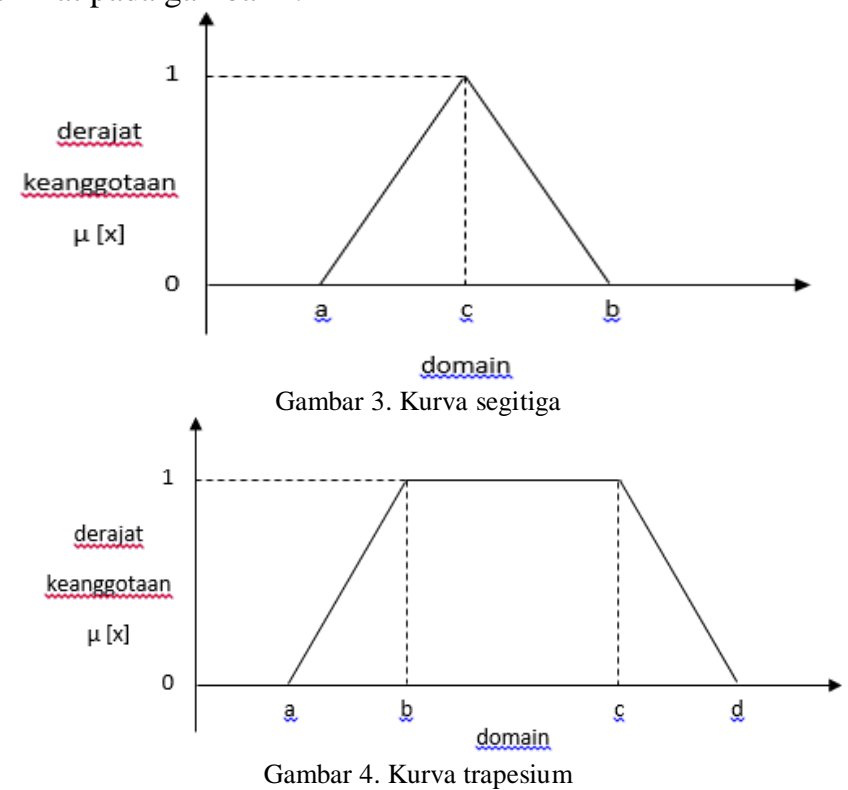

2) Fuzzy Inference System (FIS) :

Sistem Inferensi Fuzzy (FIS) adalah sistem yang mengevaluasi semua rule secara simultan pada Logika Fuzzy

I Made Teguh Winasatria: Economic Dispatch Pada Pembangkit... untuk menghasilkan kesimpulan. Semua aturan atau rule harus didefinisikan terlebih dahulu sebelum menyusun sebuah FIS yang akan digunakan untuk menginterprestasikan sebuah rule tersebut. Terdapat 3 jenis FIS pada Logika Fuzzy yang biasa digunakan yaitu Mamdani, Sugeno dan Tsukamoto [11]. Namun pada penelitian ini digunakan jenis FIS Mamdani.

\section{E. Hasil Penelitian Terkait}

Penelitian ini didasari oleh beberapa penelitian yang sudah ada sesuai dengan permasalahan yang sama namun menggunakan metode yang berbeda, diantaranya adalah:

1. Penelitian berjudul "Pembebanan Operasi Ekonomis Pada Sistem Tiga Pembangkit Termal: Menggunakan Metode Analitik dan Logika Fuzzy" yang dilakukan oleh Suranjana Bharadwaj; dan Bipul Kumar Talukdar, dimana penelitian yang dilakukan pada tahun 2016 ini membahas perbandingan nilai pembebanan operasi ekonomis dengan menggunakan metode Analitik dan Logika Fuzzy. Hasil yang didapat dari penelitian ini adalah bahwa solusi analitis menunjukkan hasil yang lebih baik dibandingkan dengan metode Logika Fuzzy.

2. Penelitian berjudul "Operasi Ekonomis Pembangkit Thermal Sistem 500 KV Jawa-Bali Dengan Pendekatan Algoritma Fuzzy Logic" yang dilakukan oleh Riva Nihayatul Marifah; Yadi Mulyadi; dan Ade Gafar Abdullah; Program Studi Pendidikan Teknik Elektro FPTK UPI; 2013, membahas mengenai operasi ekonomis (Economic Dispatch) pada pembangkit thermal sistem 500 KV Jawa-Bali menggunakan Algoritma Logika Fuzzy. Pada penelitian ini mendapat kesimpulan bahwa penjadwalan unit pembangkit dengan pendekatan Algoritma Logika Fuzzy memberikan hasil biaya 23,27\% lebih ekonomis dibandingkan dengan penjadwalan dengan data riil sistem.

\section{METODE PENELITIAN}

Penyelesaian permasalahan Economic Dispatch menggunakan metode FLC disimulasikan menggunakan aplikasi Matlab versi R2016a. Langkah awal penelitian adalah membuat pemodelan FLC analisis Economic Dispatch. Kemudian membuat algoritma Fuzzy Logic untuk dapat memberikan solusi yang lebih baik. Hasil simulasi kemudian dibandingkan dengan hasil dari Real System dan metode Iterasi Lamda. Pemodelan FLC dan alur analisis penelitian ini diuraikan pada gambar 5 dan 6.

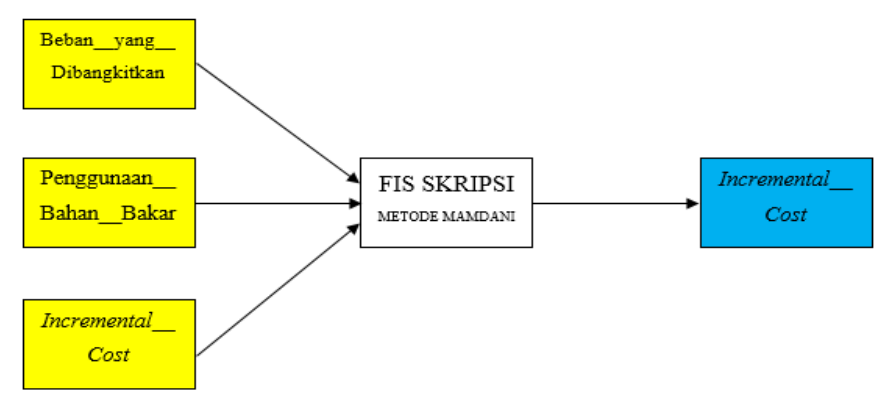

Gambar 5. Pemodelan Logika Fuzzy

\section{A. Alur Analisis Penelitian}

p-ISSN:1693 - 2951; e-ISSN: 2503-2372 


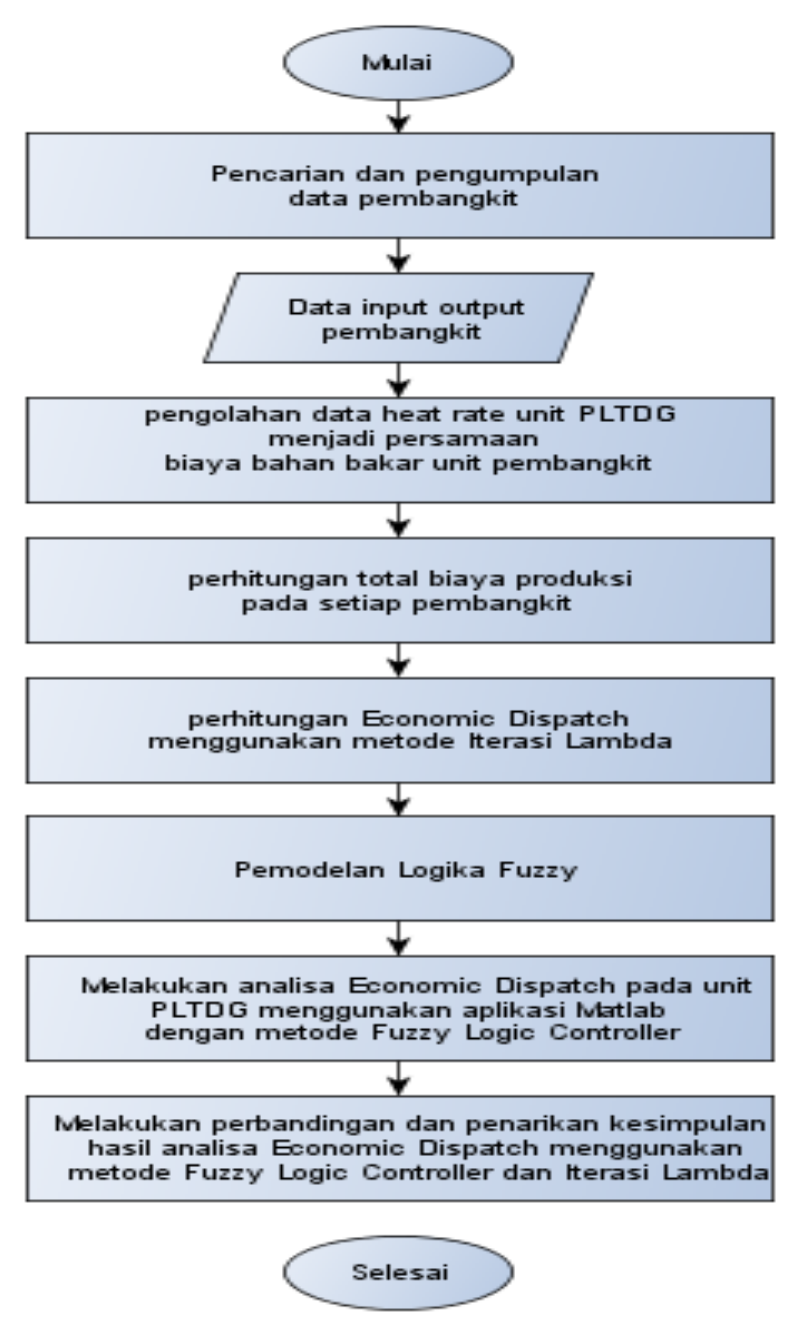

Gambar 6. Alur Analisis Metode Penelitian

III. HASIL DAN PEMBAHASAN

Sebelum melakukan perhitungan Economic Dispatch perlu diketahui besar permintaan beban (PD). Tabel berikut merupakan permintaan beban yang dibangkitkan unit PLTDG per tanggal 30 September 2017 tiap jam:

TABEL I

BEBAN HARIAN TOTAL UNIT PLTDG TANGGAL 30 SEPTEMBER

\begin{tabular}{|c|c|c|}
\hline Tanggal & Jam & Beban (MW) \\
\hline $09 / 30 / 17$ & 00.00 .00 & 99,2 \\
\hline $09 / 30 / 17$ & 01.00 .00 & 99,2 \\
\hline $09 / 30 / 17$ & 02.00 .00 & 98,9 \\
\hline $09 / 30 / 17$ & 03.00 .00 & 96,2 \\
\hline $09 / 30 / 17$ & 04.00 .00 & 98,5 \\
\hline $09 / 30 / 17$ & 05.00 .00 & 98,6 \\
\hline $09 / 30 / 17$ & 06.00 .00 & 98,6 \\
\hline $09 / 30 / 17$ & 07.00 .00 & 98,6 \\
\hline $09 / 30 / 17$ & 08.00 .00 & 98,6 \\
\hline $09 / 30 / 17$ & 09.00 .00 & 98,6 \\
\hline $09 / 30 / 17$ & 10.00 .00 & 98,6 \\
\hline
\end{tabular}

\begin{tabular}{|l|l|l|}
$09 / 30 / 17$ & 11.00 .00 & 112,6 \\
\hline $09 / 30 / 17$ & 12.00 .00 & 112,8 \\
\hline $09 / 30 / 17$ & 13.00 .00 & 112,8 \\
\hline $09 / 30 / 17$ & 14.00 .00 & 112,8 \\
\hline $09 / 30 / 17$ & 15.00 .00 & 112,8 \\
\hline $09 / 30 / 17$ & 16.00 .00 & 112,8 \\
\hline $09 / 30 / 17$ & 17.00 .00 & 112,8 \\
\hline $09 / 30 / 17$ & 18.00 .00 & 117,8 \\
\hline $09 / 30 / 17$ & 19.00 .00 & 157,8 \\
\hline $09 / 30 / 17$ & 20.00 .00 & 141,2 \\
\hline $09 / 30 / 17$ & 21.00 .00 & 112,8 \\
\hline $09 / 30 / 17$ & 22.00 .00 & 104,6 \\
\hline $09 / 30 / 17$ & 23.00 .00 & 99,4 \\
\hline
\end{tabular}

\section{A. Karakteristik input-output pembangkit}

Karakteristik input-output unit PLTDG didapat dari data pembebanan performance test tiap blok unit PLTDG milik PT. Indonesia Power UPJP Bali dari 50\%, 75\%, 80\% dan 100\% data SFC (Specific Fuel Consumption) dengan daya terpasang tiap-tiap blok unit pembangkit. SFC adalah besar konsumsi bahan bakar dalam membangkitkan daya (MMBTU/MWh). Tabel berikut adalah hasil proses perhitungan dalam mencari persamaan karakteristik input-output tiap blok unit PLTDG:

TABEL II

PERSAMAAN KARAKTERISTIK INPUT-OUTPUT TIAP BLOK UNIT PLTDG

\begin{tabular}{|c|c|c|c|}
\hline \multirow{2}{*}{$\begin{array}{c}\text { UNIT PLTDG } \\
\text { Pesanggaran }\end{array}$} & \multicolumn{3}{|c|}{ Koefisien Biaya Bahan Bakar } \\
\cline { 2 - 4 } & $\mathbf{a}_{\mathbf{i}}$ & $\mathbf{b}_{\mathbf{i}}$ & $\mathbf{c}_{\mathbf{i}}$ \\
\hline PLTDG BLOK 1 & 12301 & 139758 & 25351320 \\
\hline PLTDG BLOK 2 & 7635 & 443838 & 21063631 \\
\hline PLTDG BLOK 3 & 4050 & 721710 & 15763849 \\
\hline PLTDG BLOK 4 & 126 & 968302 & 12117181 \\
\hline
\end{tabular}

B. Economic Dispatch dengan Metode Iterasi Lamda

Berdasarkan nilai persamaan karakteristik input-output tiap blok unit PLTDG, perhitungan Economic Dispatch menggunakan metode Iterasi Lamda pada tanggal 30 September 2017 pukul 00.00 dan 01.00 yang membangkitkan beban sebesar 99,2 MW, didapatkan hasil perhitungan optimal dari total biaya produksi sebesar Rp 131.513.810,44. Perhitungan Economic Dispatch dengan menggunakan cara yang sama yaitu menggunakan metode Iterasi Lamda maka didapatkan hasil seperti tabel III beserta total biaya produksi pembangkitan dari sistem pada tanggal 30 September 2017 per jamnya.

TABEL III

HASIL ANALISIS ECONOMIC DISPATCH MENGGUNAKAN ITERASI LAMDA PADA UNIT PLTDG TANGGAL 30 SEPTEMBER 2017 PER JAMNYA

\begin{tabular}{|c|c|c|c|c|}
\hline \multirow{3}{*}{ Time } & \multicolumn{4}{|c|}{$\begin{array}{c}\text { Hasil Biaya Produksi Menggunakan } \\
\text { Metode Iterasi Lamda (Rp) }\end{array}$} \\
\cline { 2 - 5 } & $\begin{array}{c}\text { PLTDG } \\
\text { BLOK 1 }\end{array}$ & $\begin{array}{c}\text { PLTDG } \\
\text { BLOK 2 }\end{array}$ & $\begin{array}{c}\text { PLTDG } \\
\text { BLOK 3 }\end{array}$ & $\begin{array}{c}\text { PLTDG } \\
\text { BLOK 4 }\end{array}$ \\
\hline 00.00 & $44.128 .294,84$ & $45.512 .152,50$ & $41.873 .363,10$ & - \\
\hline
\end{tabular}




\begin{tabular}{|c|c|c|c|c|}
\hline 01.00 & 44.128.294,84 & $45.512 .152,50$ & 41.873.363,10 & - \\
\hline 02.00 & $44.128 .294,84$ & 45.512.152,50 & 41.640.433,00 & - \\
\hline 03.00 & 43.623.176,82 & 44.691.285,10 & $40.314 .183,45$ & - \\
\hline 04.00 & 44.031.287,29 & $45.269 .775,55$ & 41.543.516,50 & - \\
\hline 05.00 & 44.031.287,29 & 45.366.611,80 & 41.543.516,50 & - \\
\hline 06.00 & 44.031.287,29 & 45.366.611,80 & 41.543.516,50 & - \\
\hline 07.00 & 44.031.287,29 & 45.366.611,80 & 41.543.516,50 & - \\
\hline 08.00 & 44.031.287,29 & 45.366.611,80 & 41.543.516,50 & - \\
\hline 09.00 & 44.031.287,29 & $45.366 .611,80$ & 41.543.516,50 & - \\
\hline 10.00 & 44.031.287,29 & $45.366 .611,80$ & 41.543.516,50 & - \\
\hline 11.00 & $44.142 .630,21$ & 45.528.194,06 & 41.891.910,75 & 25.075.837,58 \\
\hline 12.00 & 44.144.511,97 & 45.531.225,80 & 41.897.626,25 & $25.259 .546,83$ \\
\hline 13.00 & 44.144.511,97 & $45.531 .225,80$ & $41.897 .626,25$ & $25.259 .546,83$ \\
\hline 14.00 & 44.144.511,97 & 45.531.225,80 & 41.897.626,25 & $25.259 .546,83$ \\
\hline 15.00 & 44.144.511,97 & $45.531 .225,80$ & $41.897 .626,25$ & $25.259 .546,83$ \\
\hline 16.00 & 44.144.511,97 & $45.531 .225,80$ & $41.897 .626,25$ & $25.259 .546,83$ \\
\hline 17.00 & 44.144.511,97 & $45.531 .225,80$ & $41.897 .626,25$ & $25.259 .546,83$ \\
\hline 18.00 & 44.191.585,70 & 45.607.067,86 & $42.040 .602,57$ & $29.855 .214,14$ \\
\hline 19.00 & $45.612 .912,49$ & 47.572.978,57 & $45.746 .708,11$ & $62.122 .666,54$ \\
\hline 20.00 & $44.412 .657,23$ & $45.963 .243,48$ & $42.712 .059,59$ & $51.437 .761,26$ \\
\hline 21.00 & 44.144.511,97 & $45.531 .225,80$ & 41.897.626,25 & $25.259 .546,83$ \\
\hline 22.00 & $44.067 .435,87$ & 45.407.045,97 & $41.663 .524,28$ & $11.231 .084,43$ \\
\hline 23.00 & 44.128.294,40 & $45.560 .742,40$ & $41.931 .668,50$ & - \\
\hline Total & 1.059.794.172,06 & $1.093 .420 .015,32$ & $1.006 .411 .788,59$ & $355.264 .006,22$ \\
\hline \multicolumn{3}{|c|}{ F TOTAL $=$} & \multicolumn{2}{|c|}{ Rp 3.514.889.982,19 } \\
\hline
\end{tabular}

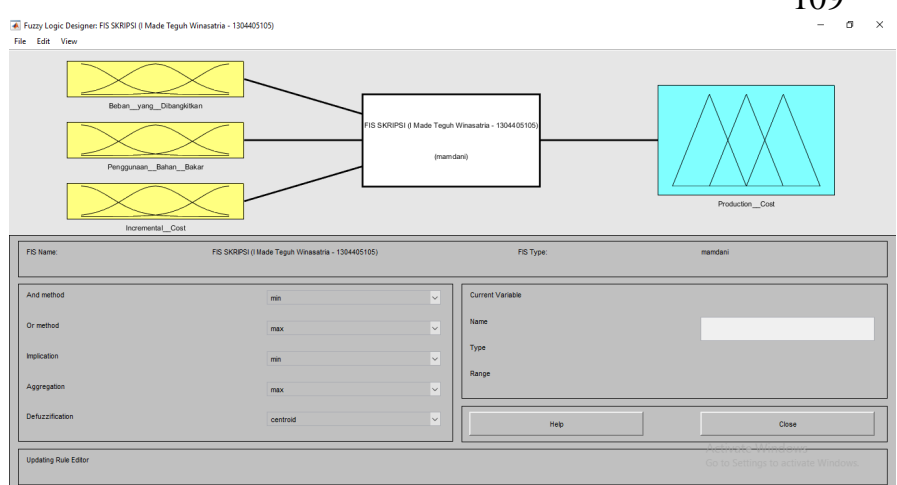

Gambar 7. Variabel input-output sistem fuzzy analisis Economic Dispatch unit PLTDG

2) Membentuk himpunan fuzzy:

Himpunan-himpunan yang dibentuk pada metode Logika Fuzzy adalah Beban yang dibangkitkan, Penggunaan bahan bakar, Incremental Cost, dan Production Cost direpresentasikan sebagai berikut:

1. Beban yang Dibangkitkan = \{Paling_Rendah, Sangat_Rendah, Rendah, Agak_Rendah, Sedang, Agak_Tinggi, Tinggi, Sangat_Tinggi, dan Paling_Tinggi\}

2. Penggunaan bahan bakar = \{Paling_Sedikit, Sangat_Sedikit, Sedikit, Agak_Sedikit, Sedang, Agak_Banyak, Banyak, Sangat_Banyak, dan Paling_Banyak\}

3. Incremental Cost $=\{$ Paling_Rendah, Sangat_Rendah, Rendah, Agak_Rendah, Sedang, Agak_Tinggi, Tinggi, Sangat_Tinggi, dan Paling_Tinggi $\}$

4. Production Cost $=\{$ Paling_Murah, Sangat_Murah, Murah, Agak_Murah, Sedang, Agak_Mahal, Mahal, Sangat_Mahal, dan Paling_Mahal\}

\section{3) Semesta Pembicaraan:}

1. Semesta pembicaraan variabel Beban yang Dibangkitkan: [14 43,8]

2. Semesta pembicaraan variabel Penggunaan bahan bakar: [48 382]

3. Semesta pembicaraan variabel Incremental Cost: [958426 1008906]

4. Semesta pembicaraan variabel Production Cost: [12 57]

4) Membentuk fungsi keanggotaan :

Basis data sangat diperlukan dalam membentuk fungsi keanggotaan karena memiliki fungsi mengatur kinerja dari proses fuzzifikasi dalam penentuan range dan nilai linguistik. Terlihat pada gambar 8 sampai gambar 10 memperlihatkan sumbu horizontal merupakan nilai dari semesta pembicaraan, dan sumbu vertikal merupakan tingkat derajat keanggotaan dari nilai variabel input.

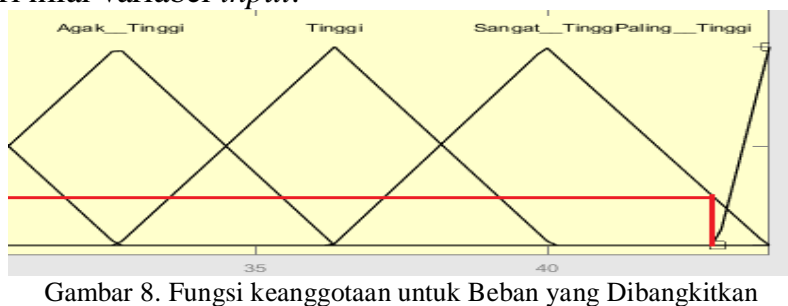

Gambar 8. Fungsi keanggotaan untuk Beban yang Dibangkitkan 


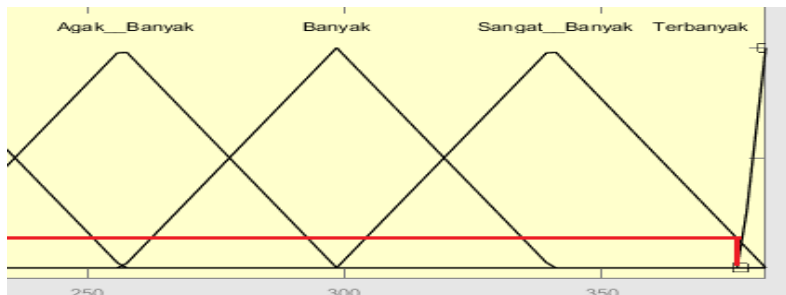

Gambar 9. Fungsi keanggotaan untuk Penggunaan Bahan Bakar

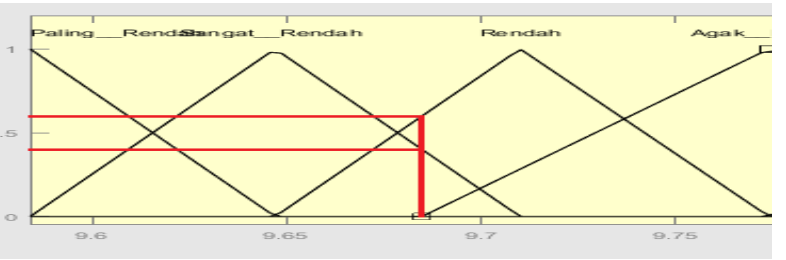

Gambar 10. Fungsi keanggotaan untuk Incremental Cost

\section{5) Membentuk basis aturan:}

Setelah membuat dan membentuk himpunan fuzzy, langkah selanjutnya yang harus dilakukan adalah pembentukan aturan fuzzy. Aturan - aturan yang dibentuk guna menyatakan relasi antara input dan output. Berikut adalah aturan fuzzy analisis Economic Dispatch tiap blok unit PLTDG yang berjumlah 729 buah aturan.

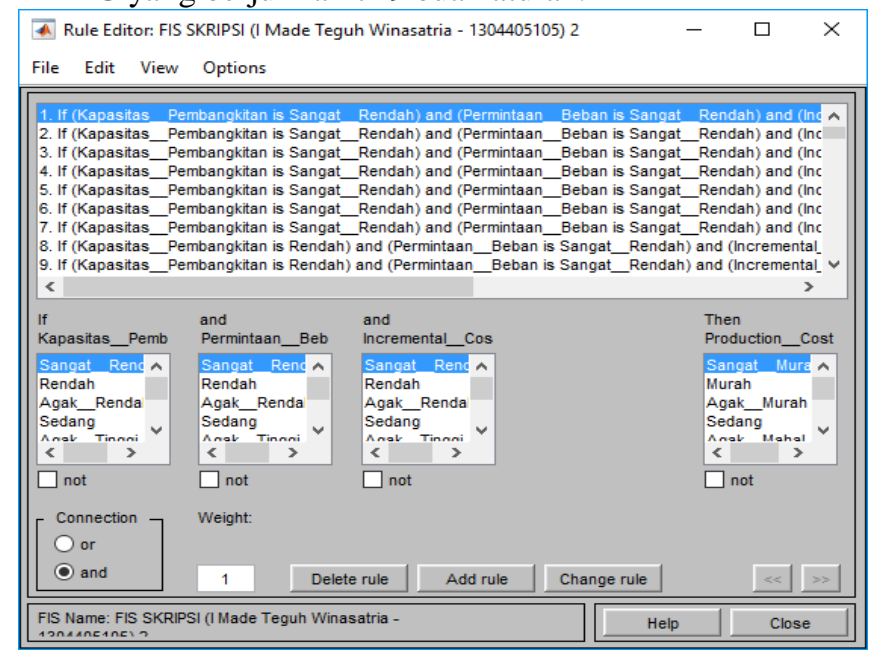

Gambar 11. Rule base sistem fuzzy analisis Economic Dispatch unit PLTDG

Setelah melalui beberapa tahapan dalam menentukan nilai output Fuzzy maka didapatkan hasil perhitungan Economic Dispatch pada unit PLTDG blok 1 menggunakan program simulasi penalaran Fuzzy dengan metode Mamdani Fuzzy Logic Controller, menghasilkan biaya produksi sebesar Rp 53.000.000,- pada jam 00.00 dan 01.00. Hasil perhitungan dengan menggunakan metode FLC dapat dilihat pada gambar 12 :

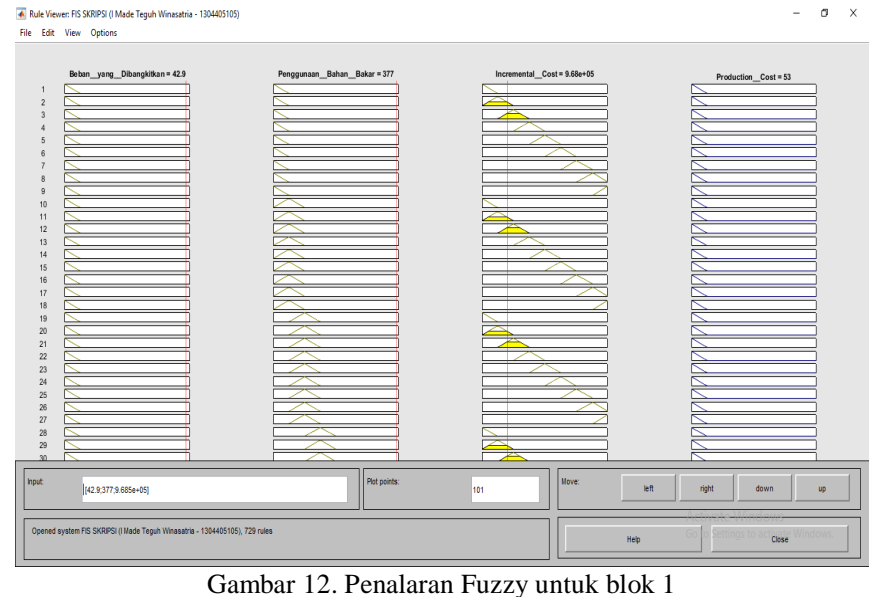

Nilai Production cost sebesar 53 tersebut, masuk dalam fungsi keanggotaan himpunan fuzzy Sangat_Mahal, sehingga dapat dikatakan hasil perhitungan Economic Dispatch pada unit PLTDG blok 1 jam 00.00 dan 01.00 dengan pembangkitan beban sebesar 42,9 MW menghasilkan biaya produksi sebesar Rp 53.000.000,--

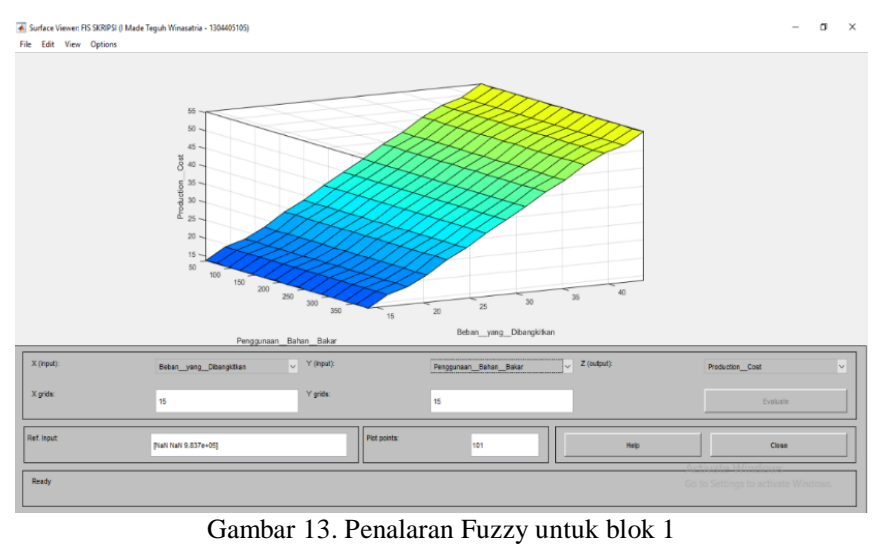

Gambar 13 diatas merupakan gambar surface viewer dimana pada gambar ini merupakan gambar pemetaan antara variabel input dan output hasil perhitungan Economic Dispatch unit PLTDG.

\section{Hasil Biaya Produksi}

TABEL IV

PERBANDINGAN HASIL BIAYA PRODUKSI

\begin{tabular}{|c|c|c|c|}
\hline Tanggal & \multicolumn{3}{|c|}{ Total Hasil Biaya Produksi (Rp) } \\
\hline $\begin{array}{c}\text { September } \\
2017\end{array}$ & $\begin{array}{c}\text { Fuzzy Logic } \\
\text { Controller }\end{array}$ & Real System & Iterasi Lamda \\
\cline { 2 - 4 } & $3.142 .600 .000,00$ & $3.271 .471 .872,21$ & $3.648 .315 .651,05$ \\
\hline
\end{tabular}

Berdasarkan tabel IV dapat dilihat bahwa hasil perhitungan Economic Dispatch menggunakan metode Fuzzy Logic Controller menghasilkan total biaya produksi yang lebih murah sebesar $\mathrm{Rp}$ 3.142.600.000,00 dibandingkan dengan hasil biaya produksi Riil Sistem sebesar Rp 3.271.471.872,21 dan metode Iterasi Lamda sebesar $\mathrm{Rp}$ 3.648.315.651,05 selama 24 jam pada tangal 30 September 2017. 


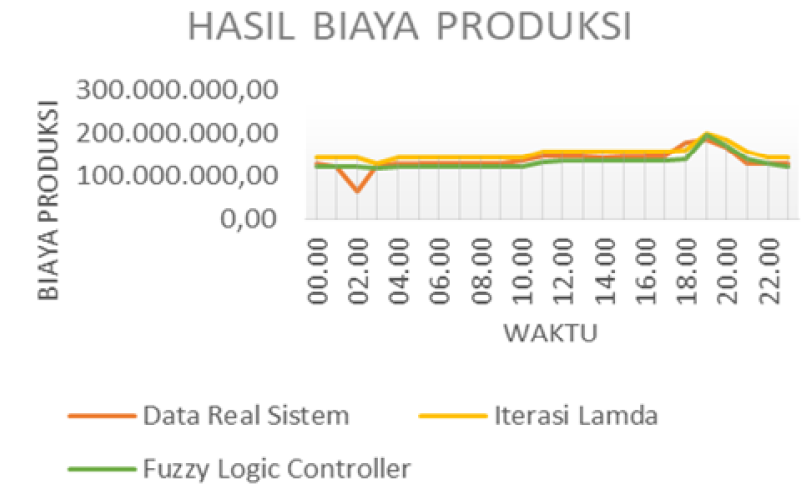

Gambar 14. Grafik perbandingan hasil biaya produksi berdasarkan data riil sistem, Iterasi Lamda, dan Fuzzy Logic Controller

Begitu pula pada gambar 14, grafik menunjukkan bahwa metode Fuzzy Logic Controller menghasilkan biaya produksi yang lebih murah dibandingkan dengan data Real System dan hasil perhitungan menggunakan Metode Iterasi Lamda. Hal ini dikarenakan proses analisis yang lebih halus pada metode FLC menggunakan himpunan-himpunan fuzzy yang berupa interval (0-1). Sedangkan perhitungan Economic Dispatch dengan menggunakan Iterasi Lamda menghasilkan biaya produksi yang lebih mahal dikarenakan pada Iterasi Lamda menggunakan syarat optimum yaitu mengoptimalkan output pembangkitan tiap blok unit pembangkit.

\section{IV.SIMPULAN}

Kesimpulan yang didapat berdasarkan hasil pembahasan Economic Dispatch pada unit PLTDG Pesanggaran menggunakan metode FIS jenis Mamdani dalam Fuzzy Logic Controller, dapat diambil kesimpulan bahwa:

1. Perhitungan Economic Dispatch menggunakan metode Iterasi Lamda selama 24 jam pada tanggal 30 September 2017 didapatkan hasil total biaya produksi pembangkitan sebesar Rp 3.514.889.982,19,-

2. Penggunaan metode Fuzzy Logic Controller pada analisis Economic Dispatch melalui 4 tahapan dalam menghasilkan nilai output. Dengan melalui 4 tahapan tersebut didapatkan hasil perhitungan Economic Dispatch dengan menggunakan metode FLC menunjukkan total biaya produksi dari hasil perhitungan Economic Dispatch dengan menggunakan metode FLC adalah sebesar Rp 3.142.600.000,-.

3. Hasil perhitungan Economic Dispatch menggunakan metode Fuzzy Logic Controller menghasilkan total biaya produksi yang lebih murah sebesar Rp 3.142.600.000,00 dibandingkan dengan hasil biaya produksi Real System sebesar Rp 3.271.471.872,21 dan metode Iterasi Lamda sebesar Rp 3.514.889.982,19 selama 24 jam pada tangal 30 September 2017. Hal ini disebabkan karena proses analisis yang lebih halus pada metode FLC menggunakan himpunan-himpunan fuzzy yang berupa interval (0-1). Sedangkan perhitungan Economic Dispatch menggunakan Iterasi Lamda menghasilkan biaya produksi yang lebih mahal karena pada Iterasi Lamda menggunakan syarat optimum yang mengoptimalkan output pembangkitan tiap blok unit pembangkit.

\section{REFERENSI}

[1] K. Syah, H. S. Dachlan, R. N. Hasanah, dan M. Shidiq, "Analisis Perbandingan Economic Dispatch Pembangkit Menggunakan Metode Lagrange dan CFPSO,” Jurnal EECCIS., vol. 6(1). 91-96. 2012.

[2] A. M. Ilyas, O. Penangsang, A. Soeprijanto, "Optimisasi Economic Dispatch Pembangkit Termal Sistem 500 kV Jawa Bali Menggunakan Modified Improved Particle Swarm Optimization (MIPSO)," National Conference: Design and Application of Technology. 2010.

[3] R. N. Marifah, Y. Mulyadi, A. G. Abdullah, "Operasi Ekonomis Pembangkit Thermal Sistem 500 KV Jawa-Bali Dengan Pendekatan Algoritma Fuzzy Logic," Electrans., vol.12(2). 127-138. 2013.

[4] A. J. Wood and B. F. Wollenberg, Power Generation Operation and Control, Singapore: John Wiley and Sons Inc, 1984.

[5] D. N. Supoma, "Penyelesaian Economic Dispatch Dengan Menggunakan Metode Particle Swarm Optimization,” (tugas akhir). Badung: Universitas Udayana. 2010.

[6] S. V. Angdrie, L. S. Patras, H. Tumaliang, F. Lisi, "Optimalisasi Biaya Bahan Bakar Untuk Penjadwalan Unit-Unit Pada Pembangkit Thermal Sistem Minahasa Dengan Metode Iterasi Lamda," 1-6. 2011.

[7] I. M. Mataram, "Unjuk Kerja Fuzzy Logic Static Synchronous Compensator (FLSTATCOM) untuk Meningkatkan Tegangan Sistem," Majalah Ilmiah Teknologi Elektro. Vol.15, No.1. (ISSN: 1963-2951). 2016.

[8] H. D. Purnomo, Logika Fuzzy, Yogyakarta: Leutikaprio, 2015.

[9] S. Kusumadewi dan H. Purnomo, Aplikasi Logika Fuzzy Untuk Pendukung Keputusan, Edisi Kedua. Yogyakarta: Graha Ilmu, 2013.

[10] S. Kusumadewi dan H. Purnomo, Aplikasi Logika Fuzzy Untuk Pendukung Keputusan, Edisi Kedua. Yogyakarta: Graha Ilmu, 2010.

[11] Yulmaini, "Penggunaan Metode Fuzzy Inference System (FIS) Mamdani Dalam Pemilihan Peminatan Mahasiswa Untuk Tugas Akhir," Jurnal Informatika., vol. 15(1): 10-23. 2015.

I Made Teguh Winasatria: Economic Dispatch Pada Pembangkit... 
[Halaman ini sengaja dikosongkan] 